\title{
Lettuce (Lactuca sativa L.) Production in Republic of Congo Using Hydroponic System
}

\author{
Romeo Ekoungoulou1 ${ }^{12^{*}}$, Espoire Brice Rahmat Mouendo Mikouendanandi ${ }^{3}$ \\ ${ }^{1}$ Ecole Nationale Supérieure d'Agronomie et de Foresterie, Université Marien Ngouabi, Brazzaville, Republic of Congo \\ ${ }^{2}$ Beijing Key Laboratory of Forest Resources and Ecosystem Process, Beijing Forestry University, Beijing, China \\ ${ }^{3}$ Department of Forest Economic and Management, School of Economic and Management, Beijing Forestry University, Beijing, \\ China \\ Email: *romeoekous@gmail.com
}

How to cite this paper: Ekoungoulou, R. and Mikouendanandi, E.B.R.M. (2020) Lettuce (Lactuca sativa L.) Production in Republic of Congo Using Hydroponic System. Open Access Library Journal, 7: e6339.

https://doi.org/10.4236/oalib.1106339

Received: April 20, 2020

Accepted: May 17, 2020

Published: May 20, 2020

Copyright $\odot 2020$ by author(s) and Open Access Library Inc.

This work is licensed under the Creative Commons Attribution International License (CC BY 4.0).

http://creativecommons.org/licenses/by/4.0/

\begin{abstract}
Hydroponic is a subset of hydroculture, which is a method of growing plants without soil by instead using mineral nutrient solutions in a water solvent. The study aimed to assess the behavior of Minetto and Blonde de Paris varieties of Lettuce (Lactuca sativa L.) in hydroculture. The experiments tanks have been installed in Talangaï Micro-garden site, located in Kimbanguiste Church at Brazzaville. The lettuce seeds were sown in a nursery tank, and then transplanted into 4 hydroponic production tanks, at the rate of 2 tanks per variety, with 20 stems per tank. Each tank has a volume of 62 l. During the 47 days of the lettuce evolutionary cycle in the production tanks, nutrient solutions were provided in two phases, namely the post-nursery and full production. About the post-nursery, $868 \mathrm{ml}$ were added, i.e. $620 \mathrm{ml}$ for the macro solution and $248 \mathrm{ml}$ for the micro solution. With regard to full production, there was an addition of $2430.4 \mathrm{ml}$, at the rate of $1736 \mathrm{ml}$ for the macro solution and $694.4 \mathrm{ml}$ for the micro solution. Statistical analysis has been made using SPSS v.18.0 and SigmaPlot v.10.0 softwares. Separations were performed by Duncan's multiple range tests. Differences at $\mathrm{P}<0.05$ were considered to be significant. The results showed that the total production was a biomass of $12 \mathrm{~kg}$, i.e. $7.6 \mathrm{~kg}$ for Minetto and $4.4 \mathrm{~kg}$ for Blonde de Paris. This study allowed us to find that Minetto fared better compared to Blonde de Paris concerning the quantitative and qualitative production of the vegetable.
\end{abstract}

\section{Subject Areas}

Agricultural Science, Food Safety, Plant Production

\section{Keywords}

Blonde de Paris, Hydroculture, Minetto, Nutrient, Tank 


\section{Introduction}

In vegetable production, lettuce (Lactuca sativa L.) occupies an important place in human food. It is cultivated for its leaves which are eaten raw or cooked by humans. Lettuce (Lactuca sativa L.) has paramount importance for humans, as it helps digestion, stimulates rejuvenation and fights against several diseases [1]. Indeed, the study of lettuce (Lactuca sativa L.) production in artificial medium is precisely hydroponics, also called above-ground cultivation [2] [3]. Here, the plant feeds on mineral elements (liquid nutrient solutions) and hydroponics therefore aim to make these minerals available to plants directly by water. Modern processes are increasingly using water as a carrier because the solid carrier (substrate) degrades easily [4]. Hydroponic fertilizers with which the formulations are so precisely dosed do not leave any toxic product or heavy metals in the plant, with an integrated phytosanitary control policy [5].

Hydroponics, by definition, is a method of growing plants in water based nutrient rich solution. Hydroponics does not use soil [6]; instead the root system is supported using an inert medium such as perlite, rock wool, clay pellets, peat moss, or vermiculite [7]. The nutrients used in hydroponic systems can come from an array of different sources, including (but not limited to) fish excrement, duck manure, or purchased chemical fertilizers [8]. This technology is of great importance in particular in the quality of vegetables, reduction of the vegetative cycle, and energy that is less spent and many others. Terrestrial plants may be grown with only their roots exposed to the nutritious liquid [9] [10], or the roots may be physically supported by an inert medium such as perlite or gravel [11] [12]. Plants commonly grown hydroponically include tomatoes, peppers, cucumbers, lettuces and marijuana.

According to growers, hydroponic systems help them in expanding their ability for continuous production in a short growing period, and require less space, and plants can be produced anywhere, i.e. in small spaces with a controlled growth environment [13]. Growers often reply that hydroponics allows them to have higher productivities and yields without any constrains of climate and weather conditions [8]. In addition, growers often claimed that quality of hydroponic produces is superior because it uses a highly controlled environment and enables a more homogeneous production without any loss of water and nutrients. Moreover, hydroponics is not dependent on seasonality, and therefore, their productivities are higher and homogenous throughout the year [5]. Growers also often report that hydroponic productions are easier, and since they do not require cultural operations such as plowing, weeding, soil fertilization, and crop rotation, they are light and clean [4].

According to [14], hydroponics is an alternative technique in which the soil is replaced by an aqueous solution containing only mineral elements required to vegetables. [7] said that plants grow in cultivation channels through which nutrient solution circulates intermittently at defined intervals and is controlled by a timer, by their own profiles for the hydroponic cultivation system [3]. Lettuce 
(Lactuca sativa L.) is the vegetable used in larger scale in hydroponics, called NFT (Nutrient Film Technique) or technique of laminar flow of nutrients [1]. This is in agreement with [15], that comment hydroponics is easy adaptation system, which has shown high performance and reductions in cycle compared to growing in soil.

The high temperatures and pressures needed for the hydrothermal liquefaction (HTL) process destroy biological and organic contaminants, such as pharmaceuticals, pathogens, and genetic material, which are present in the hydrothermal liquefaction feedstock [1] [16] [17]. Therefore, there is a high potential for post-hydrothermal liquefaction wastewater (PHW) for food crop production [1]. In closed greenhouse hydroponic cultivation systems, fertilizers are dissolved in water and the total amount of solutes in the solution is referred to as the electrical conductivity (EC). Numerous studies have examined the effect of differing electrical conductivity levels on lettuce production [11]. Previous research has indicated that increasing electrical conductivity (EC) levels resulted in a reduction of lettuce yield and leaf nitrate in a floating system but increased total phenolic compounds and antioxidant activity [11] [18].

The present work was carried out at the special program for food safety (PSSA), more precisely in Talangaï micro-garden project site, Brazzaville. The results of this study will be useful for the Food and Agriculture Organization of the United Nations (FAO), through the special program for food safety (PSSA-Congo), and the Republic of Congo's Ministry of Agriculture and Livestock. The objectives of this study were to compare the effectiveness and evolution of two varieties of lettuce, including Minetto and Blonde de Paris; and to assess the performance of lettuce (Lactuca sativa L.) in hydroponics in Talangaï.

\section{Materials and Methods}

\subsection{Study Area}

The site, in which the experiments tanks of this study have been installed in Talangaï Micro-garden site, was located in Kimbanguiste Church of Talangaï $\left(3^{\circ} 40^{\prime} \mathrm{S}, 15^{\circ} 34^{\prime} \mathrm{E}\right)$, precisely in crossroads of Marien Ngouabi street and Tchitondi road, close to Talangaï town hall in northern part of Brazzaville capital city, Republic of Congo. However, experiment was carried out with two varieties of lettuce (Lactuca sativa L.) in the same environment with four tanks, including two tanks per variety, and all the tanks had the same volume of water of $62 \mathrm{l}$. These were the Minetto and Blonde de Paris varieties: the length of these tanks was $1.24 \mathrm{~m}$, the width of $0.60 \mathrm{~m}$ and the depth of $0.10 \mathrm{~m}$. The aisle between the two varieties is $0.4 \mathrm{~m}$ and the distance between two tanks of each variety is 0.28 $\mathrm{m}$.

\subsubsection{Climate}

Brazzaville is situated at 320 meters (1050 feet) above sea level, in the south-east, along the Congo River, which gives its name to the country, daytime temperatures are about $30^{\circ} \mathrm{C}\left(86^{\circ} \mathrm{F}\right)$ from September to January, they go up to $31^{\circ} \mathrm{C} / 32^{\circ} \mathrm{C}$ 
$\left(88^{\circ} \mathrm{F} / 90^{\circ} \mathrm{F}\right)$ from February to April, and then they drop to around $27^{\circ} \mathrm{C} / 28^{\circ} \mathrm{C}$ $\left(81^{\circ} \mathrm{F} / 82^{\circ} \mathrm{F}\right)$ from June to August [19]. At night, it can be cool from June to August, while during the day it can be very hot for most of the year, but especially from mid-August to October, i.e. at the end of the dry season and before the rains begin (Figure 1); here are the average temperatures [20].

The amount of rainfall ranges from 1500 to 2000 millimeters (60 to 79 inches) per year in the north, while in the south it drops below $1500 \mathrm{~mm}$ (60 in), and reaches a low of $1200 \mathrm{~mm}$ (47 in) on the coast [19]. In the center and south, the dry season, which corresponds to the winter of the southern hemisphere, runs from June to August in the center, from June to September in the south (see Brazzaville), and from mid-May to mid-October on the coast (see Pointe-Noire). The amount of sunshine is not excellent throughout Congo, and it does not get better in the austral winter, even in the center-south where it is the dry season. On the other hand, in the period from October to April, between one rain shower and another, the sun comes out (Figure 1).

\subsubsection{Soils}

Brazzaville's soils are highly desaturated ferrallitic soils with a sandy-greasy texture. These are acidic soils and vary in $\mathrm{pH}$ from 3.5 to 5.5 [11]. Generally, we can distinguish Savannah soils, which are poor in organic matter and base; Forest soils that are more acidic than those of savannahs [21] [22], which are also richer in organic matter; Chemical analyses carried out in the laboratory of the development research institute (IRD) in Pointe-noire shows that these soils have an organic matter content that varies from $1 \%$ to $2 \%$ [11].

\subsection{Plant Material}

The seed used during the experiment was lettuce seeds of Batavia type from Tropica brand. These seeds had for average dimensions: $1.3-1.6 \times 3-4 \mathrm{~mm}$, very flattened and smooth. We used two varieties, including: Minetto variety that has black seeds in a waterproof pouch for optimal preservation of the germ quality of the seeds. The seeds in this packet weighed 4 grams with 900 seeds per gram, for a total of 3600 seeds; and Blonde de Paris variety with white seeds in a waterproof pouch for optimal preservation of the germ quality of the seeds. The seeds in this packet weighed 4 grams with 1000 seeds per gram, for a total of 4000 seeds. The seeds of Blonde de Paris are smaller than those of Minetto.

\subsection{Hydroponic Processing}

The $2 \mathrm{~cm}$ thick polystyrene (which floats on the surface of the water) is one of the elements that keep the plant in balance. It acts as insulation and float. It is cut to the right size of the tank using a sharp kitchen knife, while respecting the $2 \mathrm{~cm}$ gap between the polystyrene and the tank in the direction of length and width to facilitate manipulation during oxygenation and fertilizations. The making hole of the polystyrene was carried out using a round iron tube $(25 \mathrm{~mm}$ 


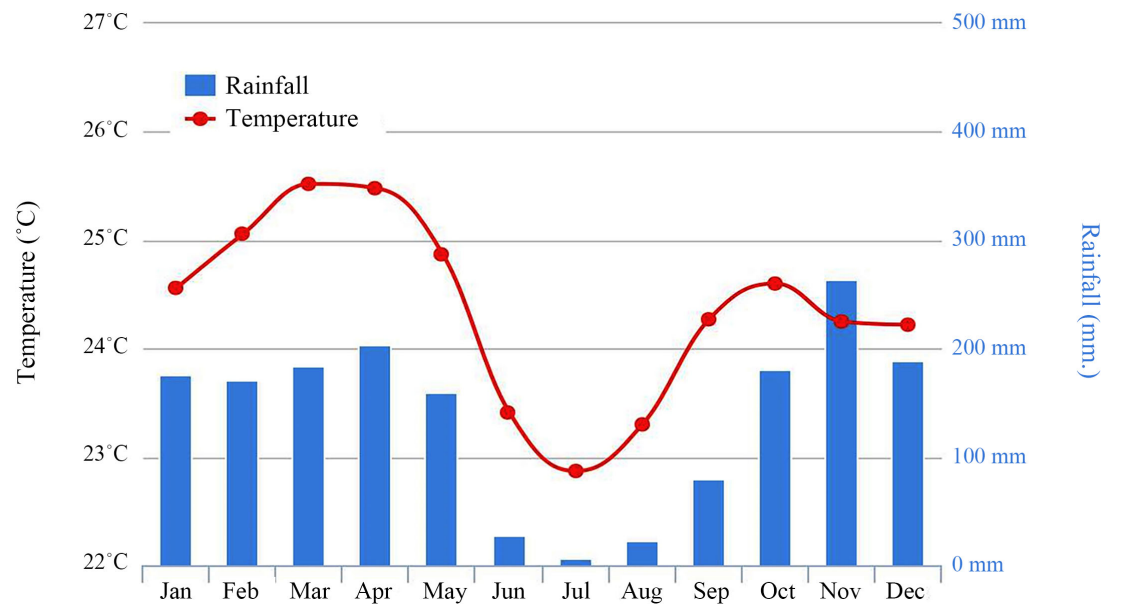

Figure 1. Climograph of the main meteorological station around the study area (Maya-maya, Brazzaville) with the mean from 1980 to 2006.

in diameter and $60 \mathrm{~cm}$ in length) hot enough on points previously marked with beverage capsules (orange pulp caps) slightly pressed on polystyrene. The spacing of the polystyrene holes obeys technical standards depending on whether it is post-nursery and production.

However, the $3 \mathrm{~cm}$ thick sponge ( $1 \mathrm{~cm}$ above the polystyrene sheet) is cut into cubes of $3 \mathrm{~cm}$ side, a little more than the diameter of the polystyrene hole. The sponge cube thus made is split from one side to $3 / 4$ with a scissor to receive the plants. The sponge ensures the balance of the plant. By pressing on the back of the wet sponge cube, the seedling is placed in the middle of the slot. The roots of the plant appear below the sponge and the leaves remain above it. The sponge containing the 5-day-old seedling is inserted into the hole without the roots getting stuck on the walls of the polystyrene. After filling through transplanting, the Styrofoam sheet should be lifted to check if all the roots are normally and arranged vertically. For fertilization in the liquid substrate, in the case of a post-nursery (from the 5th day of transplanting to the 14th day) established from a transplanting of lettuce seedlings from the nursery on solid substrate (5 days old since sowing), the day after transplanting the seedlings (6th day), we brought the half dose, i.e. $2.5 \mathrm{ml}$ of macro solution and $1 \mathrm{ml}$ of micro solution in each liter of water contained the culture tank.

The same quantities are added the following week, i.e. 7 days after the first application and 14 days after the first application. At the third week of transplanting as well as the following weeks until harvest, the doses should be alternated as follows: the fifth (1/5) dose ( $1 \mathrm{ml}$ of macro solution plus $0.4 \mathrm{ml}$ of micro solution in each liter of water in the tank) once per container and for a week and a half (1/2) dose (2.5 ml of macro solution plus $1 \mathrm{ml}$ of micro solution in each liter of water in the tank), once per tank and for a week. It should be noted that with each supply of nutritive solutions, the water in the tank is added so that each tank has a quantity of water of $62 \mathrm{l}$, because the water in the tank is often reduced by evaporation and oxygenation. 


\subsection{Setting up the Nursery}

The seeds sprouted in the petri dishes were transferred day after day to the nursery tanks to complete the germination process and continue the nursery phase. The substrate of the two nursery bins was made up of coconut fibers and peanut shells (Arachis hypogaea L.) slightly crushed. Each tank had a hole placed at the intersection of the middle line of width and that indicating the level of $2 \mathrm{~cm}$ (from the bottom of the tank to the above). Each nursery tray had two lines and each line received the seeds from a petri dish depending on the germination rhythm and varieties; the distance between the lines was $6 \mathrm{~cm}$.

The Petri dishes, until the day of transplanting the plants in the nursery, the duration were 5 days. It should be noted that no phytosanitary treatment or addition of fertilizer was carried out during this time; no pathology was registered. Watering was done every other day.

\subsection{Culture on Liquid Tanks}

The plants were put on the water until maturity. Plant roots are bathed in water enriched with solutions containing the nutrients that the plant needs for growth.

\subsubsection{Preparation of Stands}

\section{1) Preparation of Polystyrenes}

Polystyrene is a white plastic material that is often used to cover household appliances. The $2 \mathrm{~cm}$ thick polystyrene is one of the elements that keep the plant in balance. It acts as an insulator and a float. It was cut to the correct dimensions for the four tanks ( $116 \mathrm{~cm}$ long, $48 \mathrm{~cm}$ wide and $2 \mathrm{~cm}$ thick per tank) using a sufficiently hot kitchen knife. These dimensions of polystyrene are so that there is a gap of $2 \mathrm{~cm}$ between the polystyrene and the container in the direction of the length and the width to facilitate handling during the operations of oxygenation and fertilization. The beverage capsules allowed us to make a marking of the location of the plants on the polystyrene. The hole of the four polystyrenes had been operated using a round iron tube $25 \mathrm{~mm}$ in diameter and $60 \mathrm{~cm}$ of warm enough length on the points previously marked with drink capsules lightly pressed on the polystyrene. The distance between the holes of each polystyrene was $8 \mathrm{~cm}$.

\section{2) Preparation of Sponges}

The $3 \mathrm{~cm}$ thick sponge was cut into $3 \mathrm{~cm}$ cubes, a little more than the diameter of the polystyrene hole. The cube of the sponge thus made is split from one side to $3 / 4$ with a pair of scissors. It should be noted that the sponge used was simply the one that is commonly put on beds to rest on.

\subsubsection{Technical Production}

Table 1 shows that the macro solution is composed by three primary fertilizing elements, plus calcium which is a secondary fertilizer element. The micro solution on the other hand is composed by trace elements plus two secondary fertilizing elements, which are: sulphur and magnesium (Table 1). In these trace elements, chlorine is in exception. 
Table 1. Nutrient solutions composition.

\begin{tabular}{ccc}
\hline Nutrient solutions & Various components & $\begin{array}{c}\text { Nutrient solutions } \\
\text { (concentration g/l) }\end{array}$ \\
\hline \multirow{2}{*}{ Macro nutrient } & Mono ammonium phosphate $\mathrm{MAP}-\left(\mathrm{NH}_{4} \mathrm{H}_{2} \mathrm{PO}_{4}\right)$ & 34 \\
Calcium nitrate $\left(\mathrm{CaNO}_{2}\right)$ & 208 \\
Potassium nitrate $\left(\mathrm{K}_{2} \mathrm{NO}_{3}\right)$ & 110 \\
Magnesium dinitrate $\left(\mathrm{Mg}\left(\mathrm{NO}_{3}\right)_{2}\right]$ & 103.5 \\
Magnesium sulphate $\left(\mathrm{MgSO}_{4}\right)$ & 82 \\
Copper sulphate $\left(\mathrm{CuSO}_{4}\right)$ & 0.12 \\
Micro nutrient & Manganese sulphate $\left(\mathrm{MnSO}_{4}\right)$ & 0.5 \\
Zinc sulphate $\left(\mathrm{ZnSO}_{3}\right)$ & 0.3 \\
Boricacid $\left(\mathrm{H}_{3} \mathrm{BO}_{3}\right)$ & 1.55 \\
Ammonium molybdate $\left(\mathrm{NH}_{4}\right) 6 \mathrm{Mo} 0_{2}$ & 0.005 \\
Ethylenediaminetetraacetic acid $(\mathrm{EDTA})$ & 4.23 \\
\hline
\end{tabular}

\section{1) Fertilizers Necessary for the Preparation of Nutrient Solutions}

All the elements are in powder form before the solutions are prepared (Table 3). This formulation is based on the use of high purity and solubility fertilizers (Table 2). When preparing the nutritional solutions, we prepare the macro nutrient solution in relation to the micro nutrient solution. To prepare $5 \mathrm{ml}$ of macro nutrient solution, it takes $2 \mathrm{ml}$ of micro nutrient solution. So to prepare 20 liters of macro nutrient solution, we need to have 8 liters of micro nutrient solution. Table 2 and Table 3 show the amount of fertilizer required.

\section{2) Nutrient Solutions}

Two main nutrient solutions were used, including the macro nutrient solution ( $\mathrm{ml} /$ liter of water), still called by macro-elements and the micro solution ( $\mathrm{ml} /$ liter of water), and still called by micro-elements (Table 2 and Table 3). For the macro nutrient solution, three types of doses were applied: the whole dose $(5 \mathrm{ml} /$ liter of water), the half dose $(2.5 \mathrm{ml} /$ liter of water) and the fifth dose $(1 \mathrm{ml} / \mathrm{liter}$ of water). For the micro nutrient solution, three types of doses were applied: the whole dose ( $52 \mathrm{ml} /$ liter of water), the half dose ( $1 \mathrm{ml} /$ liter of water) and the fifth dose $(0.4 \mathrm{ml} /$ liter of water).

\section{a) Stage1: Post-Nursery}

\section{i) Transplanting}

The nursery plants were torn off with substrate so that the roots were not cut. After watering, the plants were soaked in a 10 liters seal that had 8 liters of water. Each plant was held by one of its two cotyledon leaves. We then pinched the tank of the water-soaked sponge cube with both fingers and placed each plant up to the collar in the middle of the crack so that the roots of the seedling appeared below the sponge and the leaf part of the plant above it. The sponge was then inserted into the polystyrene hole without the roots being wedged between the polystyrene wall and the sponge wall. This operation was carried out in the morning. The plants in the 4 tanks were transplanted to 2 tanks with the spac- 
ing's of $7 \mathrm{~cm} \times 8 \mathrm{~cm}$ for this post-nursery stage which lasts 14 days. It should be noted that all the necessary material for transplanting was prepared well before this operation. After transplanting, we lifted the polystyrene with both hands. Being opposite the position of the sun, we subsequently checked whether all the roots are free. We finally putted the polystyrene back in place.

\section{ii) Fertilization and oxygenation}

\section{Fertilization}

Fertilization is a weekly operation that involves bringing nutrients (liquid nutrient solutions) into the growing tanks. The day after transplanting, a half dose of nutrient solutions were brought into the water of each tank, i.e. $2.5 \mathrm{ml}$ of macro solution multiplied by the volume of the tank plus $1 \mathrm{ml}$ of micro solution multiplied by the volume of the tank, i.e. $155 \mathrm{ml}$ of macro solution plus $62 \mathrm{ml}$ of micro solution per tank (Table 4). Seven days after the first application, the same quantities were brought for the 2 tanks.

Table 2. Macro nutrients (to prepare 20 liters of macro nutrient solution).

\begin{tabular}{cc}
\hline Fertilizers required & Weight $(\mathrm{g})$ \\
\hline Mono ammonium phosphate MAP- $\left(\mathrm{NH}_{4} \mathrm{H}_{2} \mathrm{PO}_{4}\right)$ & 680 \\
Calcium nitrate $\left(\mathrm{CaNO}_{2}\right)$ & 4160 \\
Potassium nitrate $\left(\mathrm{K}_{2} \mathrm{NO}_{3}\right)$ & 2200 \\
\hline
\end{tabular}

Table 3. Micro nutrients (to prepare 81 of micro nutrient solution).

\begin{tabular}{cc}
\hline Fertilizers required & Weight $(\mathbf{g})$ \\
\hline Magnesium dinitrate $\left[\mathrm{Mg}\left(\mathrm{NO}_{3}\right)_{2}\right]$ & 828 \\
Magnesium sulphate $\left(\mathrm{MgSO}_{4}\right)$ & 656 \\
Copper sulphate $\left(\mathrm{CuSO}_{4}\right)$ & 0.96 \\
Manganese sulphate $\left(\mathrm{MnSO}_{4}\right)$ & 4 \\
Zinc sulphate $\left(\mathrm{ZnSO}_{3}\right)$ & 2.4 \\
Boricacid $\left(\mathrm{H}_{3} \mathrm{BO}_{3}\right)$ & 12.4 \\
Ammonium molybdate $\left(\mathrm{NH}_{4} 6 \mathrm{Mo} 7 \mathrm{O}_{2}\right)$ & 0.04 \\
Ethylenediaminetetraacetic acid $(\mathrm{EDTA})$ & 33.84 \\
\hline
\end{tabular}

Table 4. Nutrient solutions brought to post-nursery stage. $V_{1}$ is Minetto variety, $V_{2}$ is Blonde de Paris variety.

\begin{tabular}{|c|c|c|c|c|}
\hline \multirow{2}{*}{ Nutrient Solutions } & \multirow{2}{*}{ Dose } & \multicolumn{2}{|c|}{ Quantity (ml) } & \multirow{2}{*}{ Total (ml) } \\
\hline & & $\mathrm{V}_{1}$ & $\mathrm{~V}_{2}$ & \\
\hline \multirow{2}{*}{ Macro solution } & 1/2 Dose & 155 & 155 & 310 \\
\hline & 1/2 Dose & 155 & 155 & 310 \\
\hline \multirow{2}{*}{ Micro solution } & 1/2 Dose & 62 & 62 & 124 \\
\hline & 1/2 Dose & 62 & 62 & 124 \\
\hline \multicolumn{2}{|c|}{ Total } & 434 & 434 & 868 \\
\hline
\end{tabular}


Nutrient solutions are evenly distributed in the tanks. With one hand, we lifted the polystyrene and with the other hand, we mixed the substrate so that it was homogeneous. The operation was carried out in the morning or in the evening. Immediately after each addition of nutrient solutions, the water was added to the tanks so that each tank had 62 liters of liquid substrate. The macro nutrient solution is shaken before any addition to the tanks so that it is homogeneous. On the other hand, the micro solution being of a homogeneous nature was provided without being agitated.

\section{Oxygenation}

Oxygenation is an operation which consists in renewing the oxygen dissolved in the tank water. The procedure was as follows: Position yourself in front of the sun's rays; lift the polystyrene with one hand; with the other hand, fingers well apart, homogenize the entire tank then stir the water in the tank so as to form bubbles; and put the polystyrene back on the liquid substrate of the tank.

This operation was carried out in all the tanks three times per day: morning, noon, and evening. Oxygenation was done every day except on days when nutrient solutions were provided. This post-nursery stage had been carried out for 14 days, plus the 5 days of departure (nursery), which gives 19 days in total. Oxygenation was done in the post-nursery and in full production.

\section{b) Stage2: Full-Production}

On the 14th day of the plants in the 2 liquid substrate tanks, the water from these 2 tanks was poured and the 4 tanks were cleaned. The 4 tanks are then filled with water. We move on to transplanting by variety and by tank. Each tank received 20 stems of Lactuca sativa L.

\section{Fertilization and oxygenation}

The day after the water change (20th day), the half dose ( $155 \mathrm{ml}$ of macro nutrient solution plus $62 \mathrm{ml}$ of micro nutrient solution) was brought into each tank. For the following weeks and until harvest, the doses were alternated as follows: one-fifth dose ( $62 \mathrm{ml}$ of macro nutrient solution and $24.8 \mathrm{ml}$ of micro nutrient solution) for one week and half a dose ( $155 \mathrm{ml}$ of macro solution and 62 $\mathrm{ml}$ of micro solution) the following week. This dose was for all 4 tanks and with each supply of nutrient solutions, the water from the bins was added so that each tank had a water quantity of $62 \mathrm{l}$, as the water in the tanks often decreased by evaporation and oxygenation. Before each input, the macro solution is always agitated to make it homogeneous. While the micro solution that always homogeneous is brought directly (Table 5). Oxygenation was done as in the post-nursery stage in all four tanks and every day (morning, noon and evening) with the exception of the days of nutrient supply to avoid plant burns.

\subsection{Statistical Analysis}

Statistical analysis was performed using the softwares called by statistical program from social sciences (SPSS) version 18.0 and SigmaPlot version 10.0. Data were analyzed using one-way ANOVA. Separations were performed by Duncan's 
Table 5. Nutrient solutions brought to the full production stage (in $\mathrm{ml}$ ). $\mathrm{V}_{1}$ is Minetto variety and $\mathrm{V}_{2}$ is Blonde de Paris variety.

\begin{tabular}{|c|c|c|c|c|c|c|}
\hline \multirow{2}{*}{$\begin{array}{l}\text { Nutrient } \\
\text { solutions }\end{array}$} & \multirow{2}{*}{ Doses } & \multicolumn{4}{|c|}{ Quantity (ml) } & \multirow{2}{*}{ Total } \\
\hline & & $\mathrm{V}_{1} / \operatorname{tank}_{1}$ & $\mathrm{~V}_{1} / \operatorname{tank}_{2}$ & $\mathrm{~V}_{2} / \operatorname{tank}_{1}$ & $\mathrm{~V}_{2} / \operatorname{tank}_{2}$ & \\
\hline \multirow{4}{*}{$\begin{array}{l}\text { Macro nutrient } \\
\text { solution }\end{array}$} & $1 / 2$ dose & 155 & 155 & 155 & 155 & 620 \\
\hline & $1 / 5$ dose & 62 & 62 & 62 & 62 & 248 \\
\hline & $1 / 2$ dose & 155 & 155 & 155 & 155 & 620 \\
\hline & $1 / 5$ dose & 62 & 62 & 62 & 62 & 248 \\
\hline \multirow{4}{*}{$\begin{array}{l}\text { Micro nutrient } \\
\text { solution }\end{array}$} & $1 / 2$ dose & 62 & 62 & 62 & 62 & 248 \\
\hline & $1 / 5$ dose & 24.8 & 24.8 & 24.8 & 24.8 & 99.2 \\
\hline & $1 / 2$ dose & 62 & 62 & 62 & 62 & 248 \\
\hline & $1 / 5$ dose & 24.8 & 24.8 & 24.8 & 24.8 & 99.2 \\
\hline Total & & 607.6 & 607.6 & 607.6 & 607.6 & 2430.4 \\
\hline
\end{tabular}

multiple range tests. Differences at $\mathrm{P}<0.05$ were considered to be significant. The means and sample variance were equal in all experiments.

\section{Results and Discussion}

\subsection{At the Nursery Stage}

A germination test was carried out with these two varieties of lettuce (Lactuca sativa L.). The Minetto variety has a germination capacity of $96 \%$ and the Blonde de Paris of $95 \%$. This means that the seeds of the Minetto are slightly superior to that of the Blonde de Paris from the point of view of germination. Distilled water was added as there was a drop in the Petri dishes. The germinated seeds were collected once every day. These germinated seeds were transferred day after day into the 2 small tanks with solid substrate ( 51 can divided in half with $40 \%$ peanut shells (Arachis hypogaea L.) and 60\% coconut fiber). Since in the 2 varieties, the germination power exceeds $80 \%$, which means that these seeds had a good germination capacity. Thus, the intake of sprouted seeds in the solid substrate tanks of the nursery was following the rate of germination and immediately the lifting was triggered. Until the 5th day of transplanting, all plants had the same number of leaves ( 2 cotyledonary leaves). The average height of a plant was $4 \mathrm{~cm}$ for both varieties on the 5 th day.

\subsection{At the Stage of Full-Production Tanks}

\subsubsection{Height Growth}

Figure 2(a) shows that the height growth of lettuce varies from one tank to another and per treatment. The highest height was obtained with the Blonde de Paris variety $(21 \mathrm{~cm})$. Up to 30 days, there is no difference in growth rate between the varieties and between the tanks. After 30 days and until harvest, the height of the Blonde de Paris variety is higher than that of the Minetto variety $(21 \mathrm{~cm})$. 


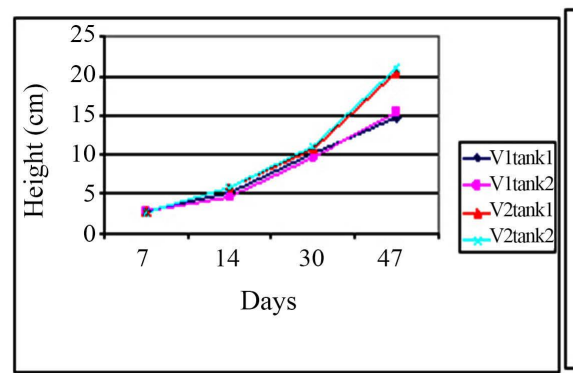

(a)

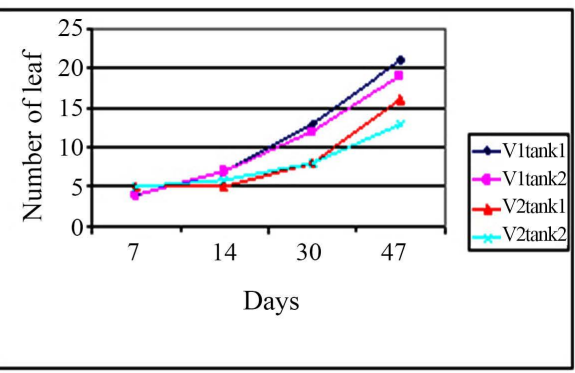

(b)



(c)

Figure 2. Height growth by variety and by tank (a). Leaf production by tank and by variety (b). Root elongation by tank and by variety (c).

\subsubsection{Foliar Production}

Figure 2(b) shows that leaf production varies depending on the variety and the tank. From the 14th day, there is a difference in foliar production which intensifies until harvest. Here it is the Minetto variety which gives the best result in the two tanks (21 leaves).

\subsubsection{Root Growth}

Figure 2(c) shows that the root elongation of lettuce varies depending on the container and the variety. Up to 14 days, there is no difference in varietal and tank root elongation. From this period, the Blonde de Paris variety has more root growth than the Minetto variety regardless of the tank. The best elongation was obtained with the Blonde de Paris variety $(17.6 \mathrm{~cm})$. Therefore, the Blonde de Paris variety has a more developed root system than the Minetto variety.

\subsection{Culture Impact on the Environment Parameters}

\subsubsection{Hydrogen Potential ( $\mathrm{pH})$}

Figure 3(a) shows the variation of $\mathrm{pH}$ over time and variety. For the Minetto variety, there are two phases: from week 1 to week 3 and from 3rd to 5th week. The $\mathrm{pH}$ goes down and then it goes up. There is then acidification of the environment and then an increase in $\mathrm{pH}$ that is close to neutrality regardless of the tank. The strongest value for the Minetto variety was 6.7. For the Blonde de Paris, there is a tank effect. The first acidic medium is slowly raised. The highest value was 5.5 .

\subsubsection{Conductivity}

Figure 3(b) shows the conductivity variation by variety over time. At the first week there it was no difference from the point of view of conductivity between 


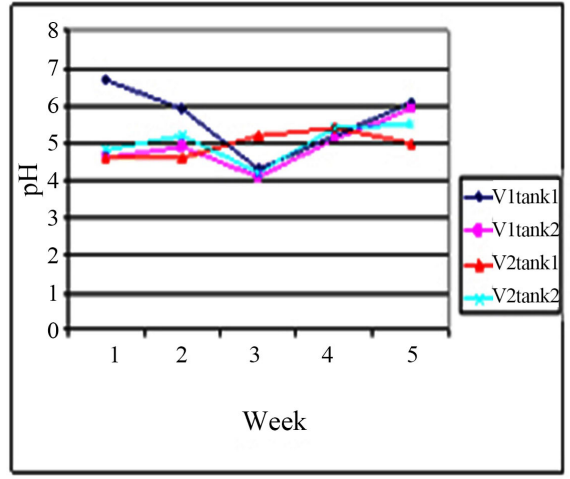

(a)

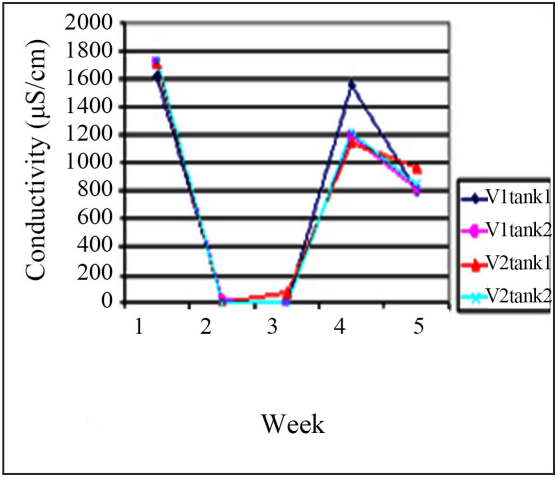

(b)

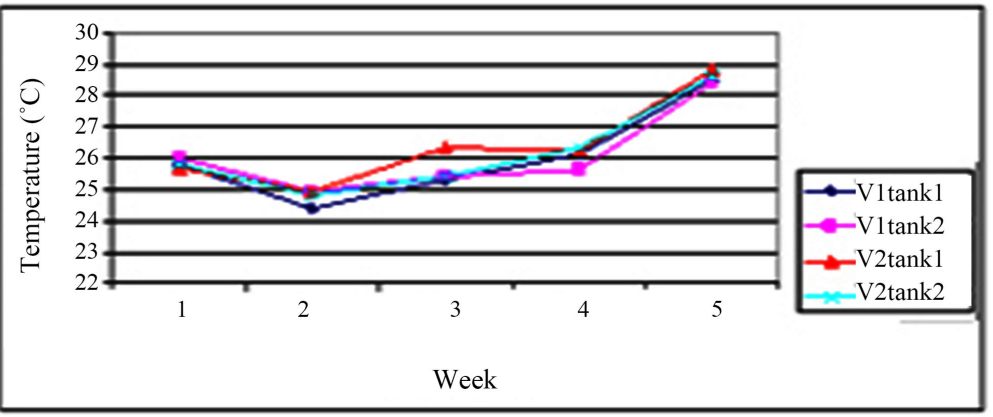

(c)

Figure 3. $\mathrm{pH}$ variation by variety and by tank (a). Conductivity variation by variety and by tank (b). Temperature variation by variety and by tank (c).

the two varieties. Generally, conductivity is higher. It drops between the 2 nd and 3 rd week, then goes back to the 4 th week at the same rate. The conductivity of the harvest was lower than that of the starting period (Figure 3). The highest conductivity was obtained with Blonde de Paris $(1719 \mu \mathrm{s} / \mathrm{cm})$. Figure 3 shows two phases of the nutrition rhythm of the varieties: a first is very intense, followed by a slowdown and subsequently a weak recovery from the first, until the harvest. The trough observed between the 2 nd and 3 rd week corresponds to the decrease in $\mathrm{pH}$ that is assumed to be root excretion which corresponds to root elongation and leaf production.

\subsubsection{Temperature}

Figure 3 (c) shows the temperature variation by tank and by variety during the experiment period. The temperature evolution [23] in the liquid substrate of four tanks has the same appearance. The highest temperature was recorded at the harvest (5th week) and more precisely in the first tank of the Blonde de Paris variety $\left(28.8^{\circ} \mathrm{C}\right)$, followed by the 2 nd tank of the same variety $\left(28.6^{\circ} \mathrm{C}\right)$.

\subsection{Biomass}

All stems of the 4 tanks were harvested with 2 tanks per variety and 20 stems per tank after 47 days (Table 6). To properly weigh, each tank had 2 lots of 10 stems with a random choice of stem (heterogeneous sample). Total production was 12 $\mathrm{kg}$, i.e. $7.6 \mathrm{~kg}$ for the Minetto variety and $4.4 \mathrm{~kg}$ for the Blonde de Paris variety. 
One stem of each lot was dried under the sun to obtain the dry weight. Figure 4 shows variety distribution of fresh biomass per stem, dry biomass per stem, and leaf production per stem. The Minetto variety appears to be the most productive (Figure 4). The difference is higher for fresh biomass $(77.5 \mathrm{~g})$ regarding two varieties studies. For leafy production, there is a difference of 5.25 , about 5 leaves per stem. For dry matter, the difference was small ( $0.05 \mathrm{~g})$.

Hydroponics is a highly exacting and demanding system that requires a greater amount of production knowledge, experience, technical skill, and financial investment than many other greenhouse systems. A grower must be committed to meeting the daily demands of production to be successful [24] [25]. However, the current study examines how nutrient solution has an influence on conductivity and lettuce growth (Figure 3 ). The highest conductivity was obtained with Blonde de Paris variety $(1719 \mu \mathrm{s} / \mathrm{cm})$. The study shows two phases of the nutrition rhythm of the varieties: a first is very intense, followed by a slowdown and subsequently a weak recovery from the first, until the harvest. The trough observed between the second and third week corresponds to the decrease in $\mathrm{pH}$ that is assumed to be root excretion which corresponds to root elongation and leaf production.

Table 6. Vegetative cycle for two varieties (in day). All phenology cycles have the same duration of 47 days regardless of the variety. $V_{1}$ is Minetto variety and $V_{2}$ is Blonde de Paris variety.

\begin{tabular}{ccccc}
\hline Varieties & Nursery & Post-nursery & Full-production & Total (Days) \\
\hline $\mathrm{V}_{1}$ & 5 & 14 & 28 & 47 \\
$\mathrm{~V}_{2}$ & 5 & 14 & 28 & 47 \\
\hline
\end{tabular}



(a)

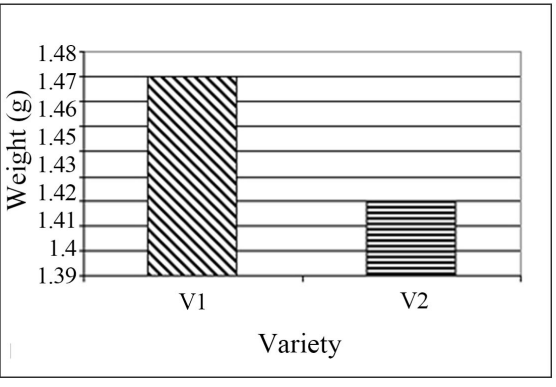

(b)

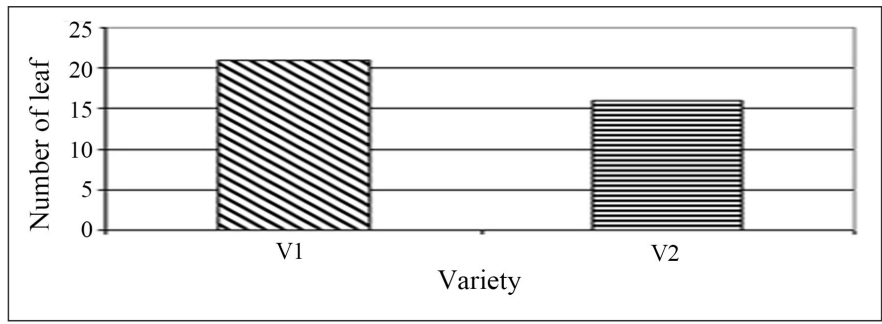

(c)

Figure 4. Average fresh biomass per stem and per variety (a). Average dry biomass per stem and per variety (b). After harvesting, the vegetables were weighed (a), and then dried in the sun to obtain dry weight (b). Average foliaceous production per stem and per variety (c). 
[18] suggested that lettuce cultivar had the greatest influence on the production of leaf FM content in green and red-leafed cultivars. Lettuce leaf DM, DM:FM ratio, and leaf water content were influenced the most by growing season, lettuce cultivar, and electro-conductivity treatments. There was an interaction between the growing season and lettuce cultivars that created the most consistent favorable conditions for the production of root biomass, root DM:FM ratio, and root water content [18]. These results are mixed with other studies that demonstrate lettuce sensitivity to increasing electro-conductivity concentrations.

[2] indicated that good water quality is required for this method, because salts may concentrate as the nutrient solution is consumed. For example, water with an initial electro-conductivity of $0.5 \mathrm{mS}$ from salt contaminants may concentrate to $2.0 \mathrm{mS}$ when 25 percent of the original nutrient solution remains, and this could lead to tip burn and other problems. Concerning water quality, [2] asserted that the use of rainwater is recommended in locations with poor water quality. If this is not possible, then deeper tanks will cause less concentration of the salts, and the tanks must be emptied after each crop.

While there are a number of different hydroponic systems that have been commercially successful for lettuce production, this profile will focus on the nutrient film technique and the floating raft method. Prospective growers should obtain as much information as they can about hydroponic production before entering into this type of enterprise.

We hope to have established a research base for future work. Hydroponics of lettuce (Lactuca sativa L.) deserves to be studied more and more with other aspects of this technology, as few people have worked on hydroponics in Congo in general and hydroponics of lettuce (Lactuca sativa L.) in Republic of Congo in particular. Thus, for a contribution to the study of hydroponics of lettuce ( Lactuca sativa L.), this work is a modest approach, but necessary because it presents itself as a milestone for future research.

\section{Conclusion}

Lettuce (Lactuca sativa L.) is one of the most commonly grown hydroponic vegetables. Also, lettuce produces by hydroponic system offer consumers to have productions with high quality, including vegetables enhanced with bioactive compounds. Both of these two varieties (Minetto and Blonde de Paris) have evolved in the same environment, with the same volume of tank water, the same dosage of nutrient solutions and the same spacing of the stem. In these 4 production tanks including 2 tanks per variety, the highest yield has been obtained with the first tank of the Minetto variety $(4 \mathrm{~kg})$, followed by the second tank of the Minetto variety $(3.6 \mathrm{~kg}$ ), then the second tank of the variety Blonde de Paris $(2.5 \mathrm{~kg})$ and the first tank of the Blonde de Paris variety $(1.9 \mathrm{~kg})$. This study attempted on the basis of research and literature investigations to analyze a number of criteria such as the physical-chemical and growth parameters of hydroponics. This study allowed us to assert that the varieties Minetto and Blonde de 
Paris of lettuce (Lactuca sativa L.) are well behaved, but the Minetto variety performed better compared to the Blonde de Paris variety from the point of view of quantitative and qualitative production of the vegetable. In addition, the various results obtained tell us that the Minetto variety is the best compared to the Blonde de Paris variety. From this work, we retain that hydroponics is of great interest compared to crops at ground level, in several aspects of comparison, in particular in work; the yield [average lettuce yield (Lactuca sativa L.) at ground level is $1 \mathrm{~kg} / \mathrm{m}^{2}$ and in hydroponics $5 \mathrm{~kg} / \mathrm{m}^{2}$ ] and quality.

\section{Acknowledgements}

The authors would like to thank National School for Agronomy and Forestry (Ecole Nationale Supérieure d'Agronomie et de Foresterie-ENSAF) from Marien Ngouabi University (Université Marien Ngouabi-https://www.umng.cg/) for supporting this study. Food and Agriculture Organization of the United Nations (FAO) also supported this work. We greatly acknowledge Jacques Ossona, Eve Sassi, Gaston Ongueme and Albert Makoutou from Food Safety Special Program (Programme Spécial pour la Sécurité Alimentaire-PSSA) for providing facilities about hydroponic experiences at Brazzaville. It is a pleasure to thank Alphonse Ngaka from Marien Ngouabi University for his considerable contribution regarding this study. Different anonymous referees have provided substantial contribution and the authors address to them their heartfelt thanks.

\section{Additional Information}

Supplementary material related to this paper is available online at: http://www.scirp.org/journal/OALibJ/.

\section{Conflicts of Interest}

The authors declare that there is no conflict of interests regarding this paper.

\section{References}

[1] Jesse, D.S., Zhang, Y.H., Margenot, J.A. and Davidson, C.P. (2019) Hydroponic Lettuce Production Using Treated Post-Hydrothermal Liquefaction Wastewater (PHW). Sustainability, 11, 1-16. https://doi.org/10.3390/su11133605

[2] Kratky, A.B. (2009) Three Non-Circulating Hydroponic Methods for Growing Lettuce. Acta Horticultural, 843, 65-72. https://doi.org/10.17660/ActaHortic.2009.843.6

[3] Carvalho, O.D.R., Weymar, N.C.L., Zanovello, B.C., Luz, S.D.G.L.M., Gadotti, I.G., Luz, S.D.A.C. and Gomes, C.M. (2015) Hydroponic Lettuce Production and Minimally Processed Lettuce. Agriculture Engineering International: CIGR Journal, 2015, 290-293.

[4] Okemwa, E. (2015) Effectiveness of Aquaponics and Hydroponic Gardening to Traditional Gardening. International Journal of Scientific Research and Innovative Technology, 2, 2313-3759.

[5] Nguyen, N.T., McInturf, S.A. and Mendoza-Cozatl, D.G. (2016) Hydroponics: A Versatile System to Study Nutrient Allocation and Plant Responses to Nutrient 
Availability and Exposure to Toxic Elements. Journal of Visualized Experiments, 113, 54317. https://doi.org/10.3791/54317

[6] Ekoungoulou, R. (2018) Managing Tropical Forest Ecosystems. Tropical Trees. Lambert Academic Publishing, Saarbrucken.

[7] Furlani, P.R. (1998) Instructions for Growing Leaf Vegetables Using Hydroponics-NFT. Agronomic Institute, IAC, Boletim Tecnico, Campinas, 168.

[8] Wambua, S.S. (2017) Reasons Why Hydroponics Is Better than Soil Farming. http://www.farmhydroponics.com/hydroponics/hydroponics-vs-soil

[9] Ekoungoulou, R., Folega, F., Mukete, B., Ifo, S.A., Loumeto, J.J., Liu, X.D. and Niu, S.K. (2018) Assessing the Effectiveness of Protected Areas on Floristic Diversity in Tropical Forests. Applied Ecology and Environmental Research, 16, 837-853. https://doi.org/10.15666/aeer/1601_837853

[10] Ekoungoulou, R., Nzala, D., Liu, X.D. and Niu, S.K. (2018) Tree Biomass Estimation in Central African Forests Using Allometric Models. Open Journal of Ecology, 8, 209-237. https://doi.org/10.4236/oje.2018.83014

[11] Ekoungoulou, R. (2006) Hydroculture of Two Varieties of Lettuce (Lactuca sativa L.) in Talangai Micro-Garden Site. Marien Ngouabi University, Brazzaville.

[12] Ekoungoulou, R., Niu, S.K., Folega, F., Nzala, D. and Liu, X.D. (2018) Carbon Stocks of Coarse Woody Debris in Central African Tropical Forests. Sustainability in Environment, 3, 142-160. https://doi.org/10.22158/se.v3n2p142

[13] Aires, A. (2018) Hydroponic Production Systems: Impact Nutritional Status and Bioactive Compounds of Fresh Vegetables. University of Tras-oas-Montes e Alto Douro, Vila Real. https://doi.org/10.5772/intechopen.73011

[14] Resh, H.M. (1997) Hydroponic Crops: New Production Techniques. 4 Edition, Ediciones Mundi-Prensa, Madrid.

[15] Ohse, S., Dourado, N.D., Manfron, A.P. and Santos, S.O. (2001) Qualidade de alface produzidos em hidroponia. Scientia Agricola, 58, 181-185.

https://doi.org/10.1590/S0103-90162001000100027

[16] Peterson, A., Vogel, F., Lachance, R.P., Froling, M., Antal Jr., M.J. and Tester, J.W. (2008) Thermochemical Biofuel Production in Hydrothermal Media: A Review of Sub- and Supercritical Water Technologies. Energy Environmental Science, 1, 32-65. https://doi.org/10.1039/b810100k

[17] Huang, H.J. and Yuan, X.Z. (2015) Recent Progress in the Direct Liquefaction of Typical Biomass. Progress in Energy Combustion Science, 49, 59-80. https://doi.org/10.1016/j.pecs.2015.01.003

[18] Sublett, L.W., Barickman, C.T. and Sams, E.C. (2018) The Effect of Environment and Nutrients on Hydroponic Lettuce Yield, Quality, and Phytonutrients. Horticulturae, 4, 1-15. https://doi.org/10.3390/horticulturae4040048

[19] ANAC (2007) Annual Report of National Agency of Civil Aviation. National Agency of Civil Aviation (ANAC), Brazzaville.

[20] Ekoungoulou, R. (2014) Carbon Stocks Evaluation in Tropical Forest, Congo. Carbon Stocks in Forest Ecosystems. Lambert Academic Publishing, Saarbrucken.

[21] Ekoungoulou, R., Niu, S.K., Loumeto, J.J., Ifo, S.A., Bocko, Y.E., Mikieleko, F.E.K., Guiekisse, E.D.M., Senou, H. and Liu, X.D. (2015) Evaluating the Carbon Stock in Above- and Below-Ground Biomass in a Moist Central African Forest. Applied Ecology and Environmental Sciences, 3, 51-59.

[22] Ekoungoulou, R., Nzala, D., Liu, X.D. and Niu, S.K. (2017) Ecological and Structural Analyses of Trees in an Evergreen Lowland Congo Basin Forest. International 
Journal of Biology, 10, 31-43. https://doi.org/10.5539/ijb.v10n1p31

[23] Ekoungoulou, R., Liu, X.D., Loumeto, J.J., Ifo, S.A., Bocko, Y.E., Koula, F.E. and Niu, S.K. (2014) Tree Allometry in Tropical Forest of Congo for Carbon Stocks Estimation in Above-Ground Biomass. Open Journal of Forestry, 4, 481-491.

https://doi.org/10.4236/ojf.2014.45052

[24] Ekoungoulou, R., Liu, X.D., Ifo, S.A., Loumeto, J.J. and Folega, F. (2014) Carbon Stock Estimation in Secondary Forest and Gallery Forest of Congo Using Allometric Equations. International Journal of Scientific and Technology Research, 3, 465-474.

[25] Ekoungoulou, R., Liu, X.D., Loumeto, J.J. and Ifo, S.A. (2014) Tree Above- and Below-Ground Biomass Allometries for Carbon Stocks Estimation in Secondary Forest of Congo. Journal of Environmental Science, Toxicology and Food Technology, 8, 9-20. https://doi.org/10.9790/2402-08420920 